Bangladesh J. Bot. 44(2): 209-214, 2015 (June)

\title{
RAPID MASS MULTIPLICATION OF GLOMUS MOSSEAE INOCULUM AS INFLUENCED BY SOME BIOTIC AND ABIOTIC FACTORS
}

\author{
Subrata Nath Bhowmik*, Gulab Singh Yadav and Mrinmay Datta \\ Division of Natural Resource Management, ICAR Research Complex for NEH Region, \\ Tripura Centre, Lembucherra 799210, Tripura, India
}

Key words: Rapid mass multiplication, Glomus mosseae, Biotic, Abiotic factors, Root colonization

\begin{abstract}
Rhodes grasses (Chloris gayana Kunth) inoculated with Glomus mosseae were grown under the influence of Azospirillum (biotic factor), IAA (abiotic factor) and Hoagland's solution (abiotic factor). The effectiveness of each factor was evaluated by measuring mycorrhizal root colonization and spore numbers. The pot culture experiment was carried out under polyhouse condition and observations were recorded at 45, 90 and 120 days of plant growth. The harvest date finely influenced the size of mycorrhizal inoculum. But, all biotic and abiotic factors had a greater influence on root colonization and spore multiplication than harvest time. The agents on application in conjunction favourably enhanced root infection and spore multiplication as compared to their solo treatments, with Azospirillum + Hoagland's solution application posing to be the best. This not only stimulated mycorrhizal development, but also accelerated the root growth.
\end{abstract}

\section{Introduction}

Arbuscular mycorrhizae (AM) are obligate biotrophic fungi forming symbiotic relationship with the roots of many plants. Despite immense potential of AM fungus to increase crop yield, the obligate biotrophic nature of AM fungus has complicated the development of cost-efficient large scale production methods to obtain high-quality AM fungal inoculum (IJdo et al. 2010). AM fungal propagules comprising mycelium or infected root pieces, and soil borne spores are termed as inoculum (Daniels and Skipper 1982).

Several cultural techniques viz., pot culture, soilless culture, hydroponic culture, aeroponic culture, and root organ culture based on this constraint are applicable for commercial scale production of AM inoculum (Jarstfer and Sylvia 1992). These are two-member (plant and fungus) systems, technically feasible and hold commercial potential. But importantly, all of them involve extended culture periods of several months, making AM inoculants relatively expensive to produce. As such, development of rapid and more efficient culture system remains an important challenge for commercialization.

The mycorrhizal colonization and subsequent spore multiplication are solely influenced by biotic factors (presence of microorganisms qualitatively, and quantitatively) (Bhowmik and Singh 2004); abiotic factors (temperature, presence of heavy metals, soil nutrient status, $\mathrm{pH}$, moisture etc.) in its ecological niche (Douds et al. 2006) and harvest date (Al-Raddad 1995) among many others. However, optimization of biotic factor(s) with abiotic factor(s) to maximize AM inoculum in a short time is meager. Here the possible use of Azospirillum (biotic factor) with IAA and Hoalgland's solution in probable combinations and optimized AM fungal root colonization and sporulation in a short period was explored. In order to deduce the best time for harvesting AM inoculum; the relationship of root infection, and spore production to plant age was also recorded.

*Author for correspondence: $<$ snb70@yahoo.co.in>. 


\section{Materials and Methods}

A culture of Glomus mosseae (Nicol. and Gerd.) Gerd. and Trappe (Gerdemann and Trappe 1974) was obtained from Native Plant Institute, Salt Lake City, Utah, USA and maintained as a pure stock-plant culture in pots containing sterilized soil and sand (3:1) (Barea et al. 1983) using Rhodes grass (Chloris gayana Kunth) as a host for four months. Spores were collected by wetsieving and decanting the root zone soil (Gerdemann and Nicolson 1963). Healthy pale yellowbrown coloured spores were selected with the aid of stereomicroscope and were surface sterilized in Chloramine-T $(2 \% \mathrm{w} / \mathrm{v})$ for 20 min and rinsed 3 - 4 times in sterile deionized water. The test microbe Azospirillum sp. R. v. zae, isolated from sporocarp of ecto-mycorrhizal fungus (Rhizopogan vinicolar) (courtesy Dr. J. Dobereiner, Embrapa Agrobiology, Rio de Janeiro, Brazil) was maintained and cultured in Okon's medium (Lakshmi Kumari et al. 1980). The organism was grown in specified medium $\left(50 \mathrm{ml}\right.$ ) in $250 \mathrm{ml}$ conical flasks in shaking incubator (at $28 \pm 2^{\circ} \mathrm{C}$ for one day) to achieve a final concentration of $10^{8}$ cells $/ \mathrm{ml}$. IAA was obtained pure (HiMedia Laboratories Pvt. Ltd., India). The stock solution of IAA $(100 \mu \mathrm{g} / \mathrm{l})$ in sterile deionized water on preparation was nitrocellulose filter $(0.22 \mu \mathrm{m}$ pore diameter) sterilized and stored in refrigerator for future study. N-free Hoagland's solution was prepared at a concentration as described by Steiner and van Winden 1970. Fifty millitre of Hoagland's solution in conical flask (100 ml ca.) was attained by autoclaving at $15 \mathrm{psi}$ for $15 \mathrm{~min}$. Seeds of Rhodes grass were obtained from the Division of Agronomy, Indian Agricultural Research Institute (IARI), New Delhi. The grass seeds were surface sterilized with $0.01 \% \mathrm{HgCl}_{2}$ for $4 \mathrm{~min}$, washed ten times with sterile deionized water and dried on blotting paper under sterile condition.

AM root colonization and sporulation studies were carried out in sterilized (1.5\% Sumabac sanitizer) plastic pots (6" diameter) containing sterilized soil and sand (3:1) (Barea et al. 1983)@ $2 \mathrm{~kg} /$ pot. Sandy loam soil ( $2 \mathrm{~mm}$ mesh size) having $0.52 \%$ total organic carbon, $0.04 \%$ total nitrogen, $5 \mathrm{ppm} \mathrm{NaHCO}_{3}{ }^{-}$extractable $\mathrm{P}, 1.5 \%$ moisture and $6.5-7.5 \mathrm{pH}$ was used. The potting soil at $1 \mathrm{~cm}$ depth was removed from diazotroph designated pots and mixed thoroughly with Azospirillum preparation $(50 \mathrm{ml})$ and left for light drying. Twenty holes (approximately $0.5 \mathrm{~cm}$ wide and $1 \mathrm{~cm}$ deep) were made on the surface of soil in same pots and 50 sterile G. mosseae spores were pipetted into each hole followed by sowing of one sterile Rhodes grass seed. The open seeded holes were then covered evenly with the preparation of diazotroph mixed soils to give rise to solo Azospirillum treatment. The solo treatments of IAA and Hoagland's solution were accomplished by pipetting 1 and $2 \mathrm{ml}$ of their stock solutions, respectively to each mycorrhiza loaded seed holes. The probable compounding of microbial culture, phytohormone, and nutrient solution under study gave rise to set of combination treatments viz., Azospirillum + IAA, Azospirillum + Hoagland's solution, IAA + Hoagland's solution, and Azospirillum + IAA + Hoagland's solution. The pot registering for control treatment did not receive microbial culture, phytohormone, and nutrient solution. The batch of non-AM experimental pot received similar treatments, only without G. mosseae spores. After germination, ten plants per pot were maintained. The pot culture experiment was set under semi-sterile environment in a polyhouse during March-June, where plants received an average of $8 \mathrm{hrs}$ day light with a mean ambient temperature of $30.8^{\circ} \mathrm{C}$. The pots were irrigated with sterile deionized water throughout the experiment. The experiment was completely randomized design; each treatment replicated nine times i.e., three replicates for the first harvest 45 days after sowing (DAS), three replicates for the second harvest (90 DAS), and three replicates for the third harvest (120 DAS).

Roots of ten plants were washed, placed on blotting paper to remove excess of water and the volume of root was taken by immersing the entire roots in measuring cylinder containing water (Singh 1992). 
From the main roots, lateral roots were removed and cut into $1 \mathrm{~cm}$ pieces. The root bits from ten plants per replicate were pooled and preserved in formalin-aceto-alcohol (FAA). Fifty root sections from the composite sample were drawn at random for counting percentage AM infection by slide technique after clearing the root in $10 \% \mathrm{KOH}$ and staining with trypan blue (Phillips and Hayman 1970). The percentage root colonization was calculated by using the method of Read et al. (1976), as

Per cent root infection $=\frac{\text { No. of infected segments }}{\text { Total no. of segments examined }} \times 100$.

Spores from $25 \mathrm{~g}$ of root-zone soil samples from each replicate of a treatment were collected by wet-sieving and decanting technique, and their number was counted (Bagyaraj and Manjunath 1980).

The data were analyzed statistically using ANOVA and significant differences between treatments were separated by Duncan's test $(\mathrm{p} \leq 0.05)$.

\section{Results and Discussion}

The results in general indicate that AM spore numbers, and per cent root infection increased significantly $((\mathrm{p} \leq 0.05)$ with all treatments comprising of Azospirillum, IAA, and Hoagland's solution under study over corresponding control at all harvests (Fig. 1). The highest AM spores and root colonization were achieved by the application Azospirillum and Hoagland's solution in combination; followed by Azospirillum + IAA + Hoagland's solution, Azospirillum, Azospirillum + IAA, and IAA + Hoagland's solution. The lowest spores and root infection were recorded with the solo application of Hoagland's solution, and IAA. Mycorrhizal root colonization increased rapidly at 90 DAS, but nearly stabilized during the third harvest (120 DAS). Sporulation increased three times under the influence of all factors (by solo and dual inoculation), while 1.5 times increment was accounted in AM control at the second harvest to the first harvest. However, spore numbers dropped slightly during senescence (120 DAS) of plant growth period at some occasions. Newly formed spores exhibited a lag phase of germination and were unable to form prompt infection points, thus rendering highest spore population at the second harvest in all treatments which conforms the earlier findings of Al-Raddad (1995).
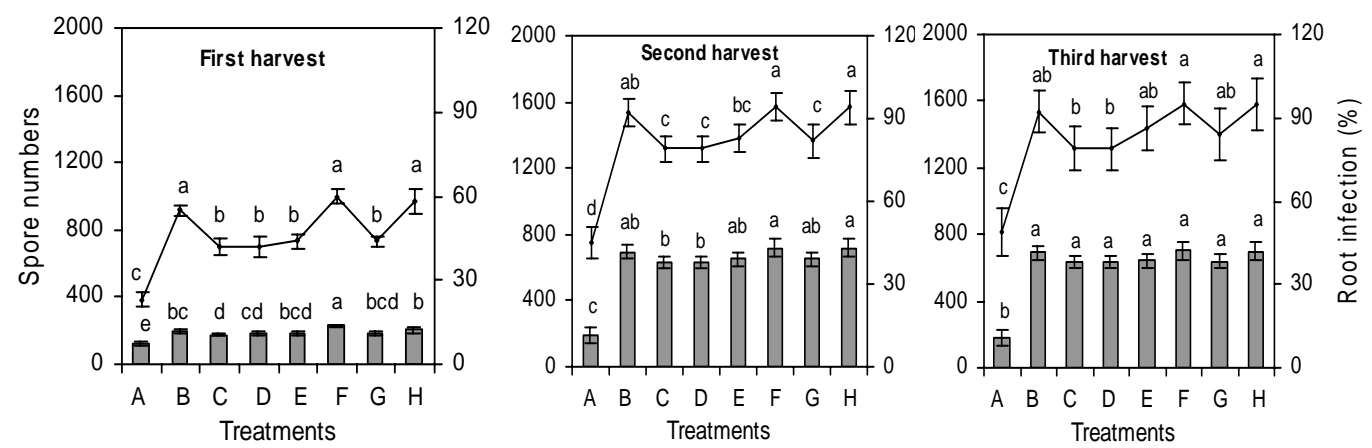

Fig. 1. Effect of Azospirillum, IAA, Hoagland's solution ( $A$ - control, $B$ - Azospirillum, $C$ - IAA, $D$ - Hoagland's solution, $E$ - Azospirillum + IAA, $F$ - Azospirillum + Hoagland's solution, $G$ - IAA + Hoagland's solution, $H$ - Azospirillum + IAA+ Hoagland's solution) on AM sporulation and root colonization in Rhodes grass at three harvests (45, 90, 120 days of plant growth). For spore numbers - $25 \mathrm{~g}$ soil sieved per pot, and root infection - 50 root sections scored per pot. Histograms represent spore numbers, line graphs represent root infection, and bars represent \pm SD of mean (of three replicates). Histograms and line graphs with a common letter are not significantly different $((\mathrm{p} \leq 0.05)$ according to DMRT. 


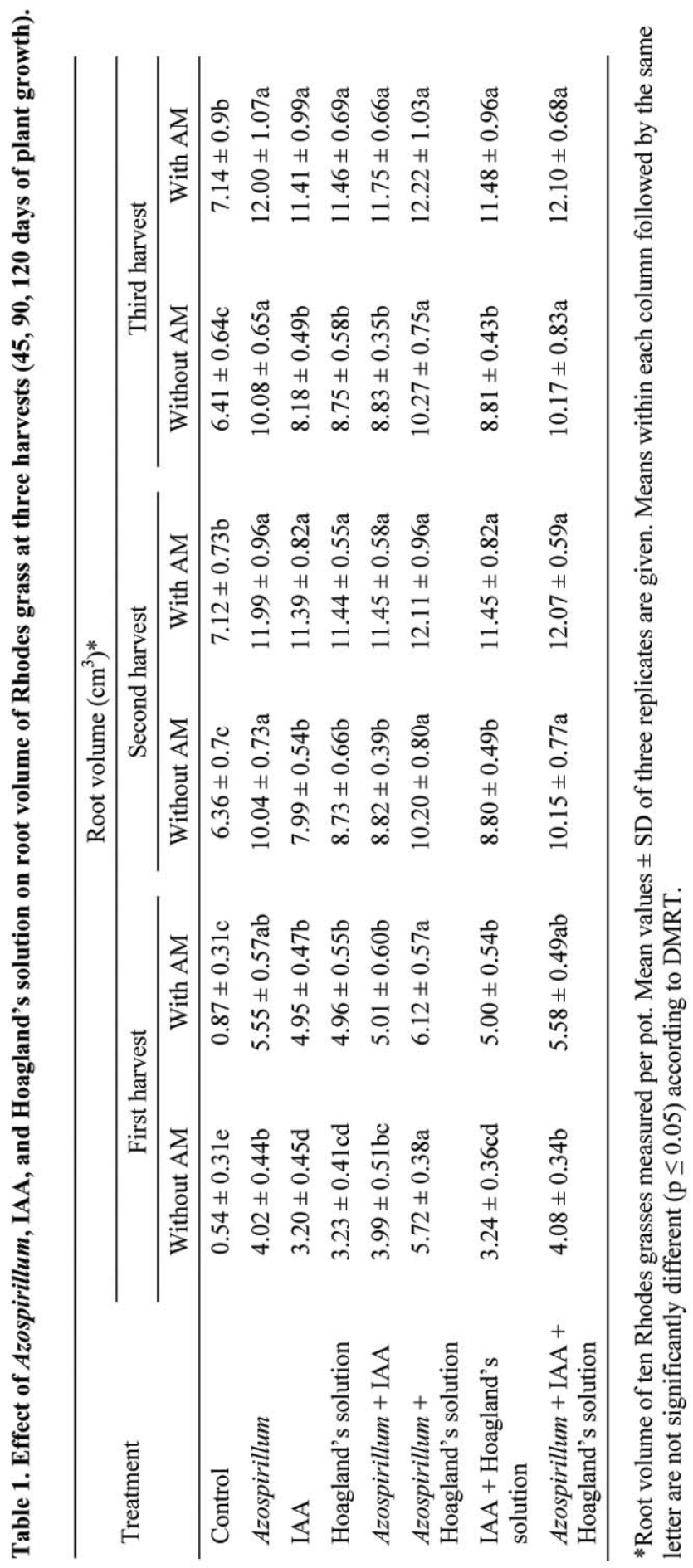


Progressive increase in root volume was parallel in mycorrhizal and non-mycorrhizal plants for the treatments with biotic and abiotic factors at the third harvest starting from 45 days after sowing (Table 1). Root growth correlated significantly with AM root colonization percentage and spore numbers at every harvest. The factors - Azospirillum, IAA, and Hoagland's solution were more effective than harvest time in increasing mycorrhizal inoculum and root volume. This could be attributed to the nutriment effect (by the factors) for appreciably proliferating roots, providing more sites for mycorrhizal infection in young plants and increasing spore numbers eventually (ElShanshoury et al. 1989). However, no significant $(\mathrm{p} \leq 0.05)$ differences between biotic and abiotic factors on root volume were noticed mostly except dual application of Azospirillum and Hoagland's solution in non-mycorrhizal Rhodes grass during the first harvest.

Combined application of the factors indicated better results than solo application except Azospirillum, whose individual application was fairly encouraging than combined treatment of IAA and Hoagland's solution. The fitness of Azospirillum could be explained in two ways. Firstly, this associative symbiont may have thrived well and performed efficiently in its natural habitat i.e., grass roots. Secondly, but more importantly besides fixing atmospheric nitrogen, Azospirillum synthesizes considerable quantities of IAA and GA in the rhizosphere which increase the root biomass (Dewan and Rao 1979), AM spore germination and hyphal elongation (Tilak et al. 1990) and root colonization (Singh 1987). Unexpectedly, the effect of dual inoculation of Azospirillum and IAA on AM production was poor. The possible cause is retardation of root development due to excess of ethylene synthesise in root zone for over accumulation of IAA in the early phase of plant growth. This finding is in conformity to the early reports of Rupp and Mudge (1985). The compounding of Azospirillum, IAA and Hoagland's solution, however poised favourable for AM mass multiplication substantially. The detrimental effect of ethylene might have been checked by nutrients of Hoagland's solution that necessitates further confirmation. Mycorrhizal plants (at 45 DAS) thus treated with the biotic and abiotic factors in probable combinations have been able to yield almost equal or even more amount of infected roots and spores than singly cultured AM (at 90 DAS). This suggests the possible reduction of AM culturing period by 45 days compared to its normal three-month pot culturing. Promoting high levels of mycorrhizal development on young, rapidly growing plants is an important challenge in commercial use of mycorrhizal inoculants. The effects observed in this work suggest that inducting Azospirillum, IAA, and Hoagland's solution in AM inoculum mass multiplication programme can be advantageous to mitigate the constraint of extended inoculum production time.

\section{Acknowledgement}

Untiring support from Mrs. Soma Nath Bhowmik in preparation of this manuscript is duly acknowledged.

\section{References}

Al-Raddad A 1995. Mass production of Glomus mosseae spores. Mycorrhiza 5: 229-231.

Bagyaraj DJ and Manjunath A 1980. Selection of suitable host for mass production of VA mycorrhizal inoculum. Plant Soil 55: 495-498.

Barea JM, Bonis AF and Olivares J 1983. Interactions between Azospirillum and VA mycorrhiza and their effects on growth and nutrition of maize and rye grass. Soil Biol Biochem. 15: 705-709.

Bhowmik SN and Singh CS 2004. Mass multiplication of AM inoculum: Effect of plant growth-promoting rhizobacteria and yeast in rapid culturing of Glomus mosseae. Curr. Sci. 86: 705-709. 
Daniels BA and Skipper HD 1982. Methods for the recovery and quantitative estimation of propagules from soil. In: Methods and principles of mycorrhizal research, NC Schenck (Ed), pp. 29-36. APS Press, St. Paul, MN.

Dewan GK and Subba Rao NS 1979. Seed inoculation of Azospirillum brasilense and Azotobacter chroococcum and the root biomass of rice (Oryza sativa L.). Plant Soil. 53: 295-302.

Douds DD Jr, Nagahashi G, Pfeffer PE, Reider C and Kayser W M. 2006. On-farm production of AM fungus inoculum in mixtures of compost and vermiculite. Bioresource Technology 97: 809-818.

El-Shanshoury AR, Hassan MA and Ablel-Ghaffar BA 1989. Synergistic effects of VAM and Azotobacter chroococcum on the growth and nutrient contents of tomato-plants. Phyton. 29: 203-212.

Gerdemann JW and Nicolson TH 1963. Spores of mycorrhizal Endogone extracted from soil by wet sieving and decanting. Trans. Br. Mycol. Soc. 46: 235-244.

Gerdemann JW and Trappe JM 1974. The Endogonaceae in the Pacific northwest. Mycol. Mem. 5: 1-76.

IJdo M, Cranenbrouck S and Declerck S 2010. Methods for large scale production of AM fungi: past, present, and future. Mycorrhiza. doi 10.1007/s00572-010-0337-z

Jarstfer AG and Sylvia DM 1992. Inoculum production and inoculation strategies for vesicular-arbuscular mycorrhizal fungi. In: Soil Microbial Ecology: Application in Agricultural and Environmental Management, FB Metting Jr. (Ed), pp. 349-377. Marcel Dekker, New York.

Lakshmi Kumari M, Lakshmi V, Nalini PA and Subba Rao NS 1980. Reactions of Azospirillum to certain dyes and their usefulness in enumeration of the organism. Curr. Sci. 49: 438-439.

Phillips JM and Hayman DS 1970. Improved procedure for clear staining parasitic and vesicular-arbuscular mycorrhizal fungi for rapid assessment of infection. Trans. Br. Mycol. Soc. 55: 158-161.

Read DJ, Koucheki HK and Hodgson J 1976. Vesicular arbuscular mycorrhiza in natural vegetation systems.1. The occurrence of infection. New Phytol. 77: 641-653.

Rupp LA and Mudge KW 1985. Ethephon and auxin induce mycorrhiza-like changes in the morphology of root organ cultures of mugo pine. Physiol. Plant. 64: 316-322.

Singh CS 1987. Enhanced formation of vesicles, arbuscules and spores through inoculation of grasses with Azospirillum brasilense and Glomus macrocarpum. In: Mycorrhiza round table: Proceedings of a national workshop. p. 334. Jwaharlal Nehru University, Delhi.

Singh CS 1992. Mass inoculum production of vesicular-arbuscular (VA) mycorrhizae: I. Selection of host in the presence of Azospirillum brasilense. Zentralbl Mikrobiol. 147: 447-453.

Steiner AA and van Winden H 1970. Recipe for ferric salts of ethylenediaminetetraacetic acid. Plant Physiol. 46: $862-863$.

Tilak KVBR, Dwivedi A and Li CY 1990. Enhancement of spore germination of Glomus fasciculatum by cell-free extracts. Ind. J. Expt. Biol. 28: 373-375.

(Manuscript received on 9 June, 2014; revised on 14 April, 2015) 